\title{
Estrogen as an Environmental Pollutant
}

\author{
L. S. Shore ${ }^{1} \cdot$ M. Shemesh ${ }^{1}$
}

Received: 15 June 2016/Accepted: 23 June 2016/Published online: 4 July 2016

(C) Springer Science+Business Media New York 2016

The paper "Estrogen as an Environmental Pollutant" appeared in the Bulletin of Environmental Contamination and Toxicology in 1993 (Shore et al. 1993). At the time it was one of the first papers to suggest that hormones excreted into the environment by humans and animals were present in sufficient quantities to disrupt the environment.

Although originally an estrogen was defined as a compound that increase the uterine weight in the rats, in recent times, the ability to bind to the estrogen receptor has become the standard (Dorfman 1962; USEPA 1998). However, the receptor is also the site for chemicals to exert their anti-estrogenic actions. In nature there are some 300 natural compounds, and even more anthropogenic compounds, which have estrogenic or anti-estrogenic activity. These environmental estrogens can be categorized into four groups: (1) naturally occurring non-steroidal plant estrogens or phytoestrogens; (2) the steroid estrogens $-17 \beta$ estradiol and estrone from animal and human sources; (3) the mycotoxins, zearalenone and zearalenol; (4) synthetic compounds with phenolic groups (Shemesh and Shore 1987; Lintelmann et al. 2003).

In cows and sheep, the most important function of estrogen is to induce estrus behavior. However, too much estrogen, hyperestrogenism, can interfere with the function of the reproductive tract. Symptoms of hyperestrogenism in cattle include nymphomania (constant behavioral estrus), ovarian cysts and premature udder development (Shore and Bar-El Cohen 2010). Estrogens are also used in animal

L. S. Shore

laurenceshores@gmail.com

1 Department of Hormone Research, Kimron Veterinary Institute, Bet Dagan, Israel husbandry to increase growth in steers. In pigs, uterine prolapse caused by zearalenone is a common phenomenon.

Phytoestrogens, in particular, are well documented to cause problems of infertility in cattle (Shemesh and Shore 1987). The function of the phytoestrogen in a legume is to signal the rhizobium to colonize the nodules. There is some evidence that the compounds may have evolved to be a mechanism to reduce fertility in foragers as well. A number of decades ago we noticed a rise in the level of coumestrol, a phytoestrogen, in alfalfa plants to levels associated with reproductive disorders. This was unrelated to any known trauma which we had previously described (Shemesh et al. 1969). It was found that the rise in coumestrol was correlated with irrigation by treated sewage water (Shore et al. 1995). When the treated sewage water was tested, estrone and $17 \beta$ estradiol were readily detected. Furthermore, using experimental hothouse and hydroponic experiments, it was shown estrone and $17 \beta$ estradiol in concentrations found in the irrigation water promoted vegetative growth (Shore et al. 1992).

In separate line of investigation, it was observed that cattle, which were fed chicken manure silaged with wheat, developed premature udders. Examination of the chicken manure showed that the amount of steroidal estrogen ingested (1 mg/9 kg of feed/day) was high enough to explain the phenomenon (Shore et al. 1988; Shemesh and Shore 1994). Other reproductive disruptions could be attributed to the testosterone present in the manure (Shemesh and Shore 1994). These steroids were persistent in the environment as there was no decrease in either the content of testosterone or estrogen following 6 months of silaging (Shore and Shemesh 1993).

In our 1993 paper in this journal, we focused on steroidal hormones since steroidal estrogens and testosterone from human and animal sources are constantly excreted 
into the environment (Lintelmann et al. 2003). For example, a pregnant woman may excrete $10 \mu \mathrm{mol} / \mathrm{day}$ of estrogen (estradiol and estrone). However, there was no information on the environmental fate of these steroids.

Because the treated water in the alfalfa experiments contained appreciable amounts of steroid, and a dose response curve in vegetative growth could be shown over a range of concentrations from 0.02 to $2 \mathrm{nml} / \mathrm{l}$ (Shore et al. 1992), we sought to determine if concentrations at this level were found elsewhere in water sources such as surface and groundwater. We also attempted to show that both farm and urban sewage effluent contained substantial amounts of steroidal estrogen.

The results indicated that estrogen was a persistent compound in the environment. It was present in both lake water used for drinking and sewage water used for irrigation at concentrations that could affect alfalfa growth. This finding of estrogen as an environmental pollutant was repeated and confirmed all over the world, indicating that estrogen and testosterone were present in several environmental compartments, including soil and groundwater (Shore and Shemesh 2003; Shore et al. 2010). One unexpected result of the 1993 publication was that John Sumpter and his colleagues who had been observing sex changes in fish in British surface waters for some years, but had not made the information public, felt they could safely publish their observations (J. Sumpter, personal communication).

The realization that hormones in physiological amounts could reach the environment, even after treatment of the sewage water, strengthened the search for the presence of pharmaceuticals and endocrine disruptor compounds in water sources. This led to the coining of the abbreviation PPCP (Pharmaceutical and Personal Care Products) by Daughton and Ternes (1999), which came to include the steroidal estrogens and pharmaceuticals contained in sewage effluent (Drewes and Shore 2001). This initiated a world-wide search to determine the hormones and pharmaceuticals present in sewage water effluent, surface and ground water. Similarly, the observation that farm effluent could contain large amounts of steroidal hormone set off a new direction in manure management. Preventing release of steroidal hormones and pharmaceuticals in manure to the environment required extensive testing under many conditions in many countries.

Subsequently, these pharmaceuticals and hormones in the environment were associated with changes in microbial ecology, increased proliferation of antibiotic resistance toward pathogens, toxicological effects in on aquatic species, and a negative effect on human health. From these developments, a book by Shore and Pruden (2009) was published that summarized hormones and pharmaceuticals generated by concentrated animal feeding operations.

\section{References}

Daughton CG, Ternes TA (1999) Pharmaceuticals and personal care products in the environment: agents of subtle change? Environ Health Perspect 107(Suppl 6):907-938

Dorfman RI (1962) Methods in hormone research, Vol. II, Part IV: standard methods adopted by official organization. Academic Press, New York

Drewes JE, Shore LS (2001) Concerns about pharmaceuticals in water reuse, groundwater recharge, and animal waste. In: Daughton CG, Jones-Lepp T (eds) Pharmaceuticals and personal care products in the environment: scientific and regulatory issues symposium series 791. American Chemical Society, Washington, DC, USA, pp 206-228

Lintelmann L, Katayama A, Kurihara N, Shore LS, Wenzel A (2003) Endocrine disruptors in the environment. Pure Appl Chem 75:631-681

Shemesh M, Shore LS (1987) Non-steroidal oestrogens of dietary origin: activity, distribution and mechanism of action. Israel $\mathbf{J}$ Vet Med 43(192):197

Shemesh M, Shore LS (1994) Effects of hormones in the environment on reproduction in cattle. In: Fields MJ, Sand RS (eds) Factors affecting net calf crops. CRC Press, Boca Raton, pp 287-298

Shemesh M, Lindner R, Ayalon N (1969) Coumestrol and 4-Omethyl-coumestrol in alfalfa grown in northern Israel: possible effect of a foliar pathogen (Pseudopeziza medicaginis lib). Refuah Vet 1969:1-7

Shore LS, Bar-El Cohen K (2010) The environmental compartments of environmental hormones. Rev Environ Health 25(4):345-350

Shore LS, Pruden A (eds) (2009) Hormones and pharmaceuticals generated by concentrated animal feeding operations: transport in water and soil. Springer, New York. ISBN 978-0-387-92833-3

Shore LS, Shemesh M (1993) Analysis of testosterone levels in chicken manure. Israel J Vet Med 48:35-37

Shore LS, Shemesh M (2003) Naturally produced steroid hormones and their release into the environment. Pure Appl Chem 75:1859-1871

Shore LS, Shemesh M, Cohen R (1988) The role of oestradiol and oestrone in chicken manure silage in hyperoestrogenism in cattle. Aust Vet J 65:67

Shore LS, Kapulnik Y, Ben Dov B, Fridman Y, Wininger S, Shemesh M (1992) Effects of estrone and $17 \beta$ estradiol on vegetative growth of Medicago sativa. Physiol Plant 84(217):222

Shore LS, Gurevich M, Shemesh M (1993) Estrogen as an environmental pollutant. Bull Environ Contam Toxicol 51:361-366

Shore LS, Kapulnik Y, Gurevich M, Wininger S, Badamy H, Shemesh M (1995) Induction of phytoestrogens production in Medicago sativa leaves by irrigation with sewage water. Environ Exp Bot 35:363-369

Shore LS, Cuneah O, Shemesh M (2010) Effects of environmental estrogens on animals in Israel: implications for effects on humans. Rev Environ Health 25(4):337-343

USEPA (1998) Endocrine disruptor screening testing advisory committee (EDSTAC), final report. https://www.epa.gov/endo crine-disruption/endocrine-disruptor-screening-and-testing-advi sory-committee-edstac-final 